\title{
CONTRIBUIÇÕES DA FILOSOFIA PÓS-EMPIRISTA AO DEBATE TEÓRICO NA GEOGRAFIA
}

Contributions of the Post-empiricist Philosophy to Theoretical Debates in Geography

Dr. Djalma Ferreira Pelegrini Empresa de Pesquisa Agropecuária de Minas Gerais Rodovia BR 050, km 63, Cx. Postal: 2248, CEP: 38.402-019 - Uberlandia (MG) Brasil Tél./Fax: (+ 55 34) 3213-8663 / 9911-8602 - djalma@epamig.br

Prof ${ }^{\mathrm{a}}$. Dr ${ }^{\mathrm{a}}$. Vânia Rúbia Farias Vlach

Universidade Fedral de Uberlândia vaniarubiavlach@yahoo.com.br

\section{aaAaa}

\begin{abstract}
Resumo
Uma revisão a respeito do tratamento dado à noção de método científico pelos filósofos pós-empiristas do século XX, como também sobre os fundamentos das ciências humanas, segundo Michel Foucault, introduziu-nos no estudo dos princípios teóricos da Geografia. A partir da análise de textos de alguns dos principais teóricos, argumenta-se que os discursos geográficos modernos colocam-se, em geral, à margem dos debates promovidos no âmbito da história e da filosofia da ciência, durante o século XX. A preocupação com a definição de método e objetos de estudos específicos para esta disciplina presta-se como evidência de que a concepção tradicional de metodologia serve ainda como fundamento para a Geografia Moderna.
\end{abstract}

Palavras-chave: Teoria da Geografia; Método Científico; Pensamento Geográfico.

\begin{abstract}
A review of the treatment given to the notion of scientific method by the post-empiricist philosophers of the twentieth century, as also of the foundations of human sciences, according to Michel Foucault, led us to the study of theoretical foundations of Geography. From the analysis of the texts of the main theorists of geography, it is argued that the modern geographical discourses are in general on the fringes of the debates held in the scope of the history and the philosophy of science during the twentieth century. The concern about the definition of method and objects of study specific to this discipline lends it self as evidence that the traditional methodology also serves as the foundation of modern geography.
\end{abstract}

Key words: Geography Theory; Scientific Method; Geographical Thought.

\section{Resumen}

Una revisión respecto el tratamiento dado a la noción de método científico por los filósofos posempiricistas del siglo XX, sino también sobre los fundamentos de las humanidades, de acuerdo com Michel Foucault, nos introdujo en el estudio de los princípios teóricos de la Geografia. A partir del análisis de textos de algunos de los principales teóricos, sostiene que el discurso geográfico moderno ponerse em general, aparte de los debates que tienen lugar dentro de la historia y la filosofía de la ciencia durante el siglo XX. La preocupación por la definición del método y los objetos de estudio específicos de esta disciplina se presta como evidencia de que la metodologia tradicional también sirve como la base de la Geografia moderna

Palabras Clave:Teoría de la Geografia, Método Científico, Pensamiento Geográfico 


\section{INTRODUÇÃO}

A publicação da Anthropogéographie, em 1882, por Friedrich Ratzel, marcou o início do processo de reflexão acerca de uma nova temática, emergente de entre os campos do conhecimento até então constituídos. A definição de Geografia dada pelos geógrafos no final do século XIX, correspondente à integração de fenômenos físicos e humanos sobre a superfície terrestre, significava, até então, uma autêntica novidade (CAPEL, 1983). Inicialmente, a temática das relações homem / meio, e da interface sociedade / natureza, chamou a atenção de muitos estudiosos, a exemplo de Friedrich Ratzel e Paul Vidal de La Blache, dentre outros da mesma vertente.

Apesar de a constituição de algumas sociedades geográficas ter ocorrido nas primeiras décadas do século XIX, os geógrafos, desde o início, encontraram dificuldades na explicitação dos métodos, na identificação do objeto de estudo, e na conceituação das categorias e noções fundamentais empregadas em suas análises. A explicitação do método e a delimitação do objeto foram procedimentos exigidos de todos os saberes que se pretenderam científicos, no referido período, segundo os critérios tradicionais. Se os teóricos da Geografia procuraram torná-la uma disciplina reconhecida nos meios acadêmicos e imprimir-lhe um caráter científico, durante os dois últimos séculos quiseram-na como conhecimento sistematizado, buscando conformá-la aos padrões metodológicos sugeridos e elegendo-lhe objetos de estudo. Portanto, a proposição de uma Geografia científica na modernidade, requereu delineamento de método e objetos compatíveis com uma suposta sistematização. É de supor que esta exigência jamais foi atendida, razão do prosseguimento desse debate nos dias de hoje.

Aponta-se, frequentemente, a grande variedade de fenômenos discutidos no âmbito da Geografia, decorrentes de processos que ocorrem na natureza e na sociedade e suas interações, como a razão da existência de grande parte das dificuldades metodológicas comumente referidas (MORAES, 1996). Entretanto, este não é um problema enfrentado apenas pelos geógrafos. Antropólogos, economistas, agrônomos, ecólogos etc, também se defrontam com ele. Ademais, a questão do método é uma discussão conduzida em todos os domínios do saber que alimentam pretensões científicas.

Horácio Capel (1983) lançou algumas luzes sobre os procedimentos adotados pelos escritores geógrafos, durante os três primeiros quartos do século XIX, apontando que a Geografia descritiva dos países, até então praticada na França, não se caracterizava pelo rigor de seu método, o que a fazia motivo de zombaria e menosprezo por parte de outros cientistas. Destaca ainda um aspecto fundamental sobre esta questão, quando informa que os geógrafos, nessa época, não adotavam um só método científico, mas uma diversidade deles, de acordo com a conveniência.

Quando Albert Demangeon (1982) propôs que os estudos em Geografia Humana fossem conduzidos a partir de uma base territorial, e que, por este detalhe, se pode distingui-la da Sociologia, certamente sugeriu um procedimento de fundamental importância para a prática dos pesquisadores geógrafos, o que, contudo, não garante a ocorrência de novas descobertas, ou, sequer, o rigor à pesquisa.

Diante da necessidade de elaborar os fundamentos da ciência geográfica, os pensadores desta disciplina percorreram diversos trajetos teóricos, durante os últimos 200 anos, em busca de terreno firme para nele implantar os alicerces de seu saber. Ousamos argumentar, neste artigo, que os desenvolvimentos alcançados neste sentido alinham os fundamentos da Geografia moderna à teoria tradicional, razão pela qual essa disciplina ainda não logrou êxito em romper o casulo de positivismo de onde foi engendrada.

\section{A QUESTÃO DO MÉTODO}

Sobre os alicerces do racionalismo e do empirismo constituíram-se os diversos saberes, identificados em conjunto pelo grande título de ciência moderna, cujo desenvolvimento tornou-se marcante a partir da revolução científica dos séculos XVI e XVII. Dos encontros e desencontros 
destas duas perspectivas de pesquisa (uma que, em tese, buscava ater-se ao pensamento e outra que, em princípio, priorizava os dados), emergiu o caudal moderno de conhecimentos, saberes, práticas e tecnologias.

A constituição da ciência se confundiu com o nascimento da modernidade, de maneira que é impossível referir-se a uma sem referir-se a outra. É esta uma das conclusões a que chegou Paulo César da Costa Gomes (1996), para quem "o pensamento científico moderno é a própria essência da modernidade, sua testemunha mais eloqüente" (GOMES, 1996, p. 66).

Os pressupostos teóricos reinantes no ambiente científico e filosófico dos séculos XVII e XVIII recomendavam a investigação científica a partir de um suposto método, que, em princípio, possibilitaria a descoberta e identificação das também supostas leis naturais. O método científico proposto, primeiramente para ser aplicado aos problemas concernentes à física, foi, posteriormente, preconizado como padrão metodológico para as pesquisas nos demais campos de estudo que emergiram em sequência durante os séculos XVIII e XIX.

A suposição da existência de um tal método, capaz de conduzir à descoberta científica, passível de ser aplicado em todos os campos do conhecimento, tem sido tomada como indicativa da abordagem positivista. A definição de métodos e a delimitação do objeto de pesquisa, procedimento que se tornou padrão em todas as disciplinas acadêmicas modernas, significa, implicitamente, o alinhamento à metodologia tradicional, herdeira, de forma predominante, do empirismo e do racionalismo, relacionada à própria lógica do pensamento moderno.

De acordo com Ivan Domingues (1991), os problemas centrais, no campo da Filosofia da Ciência, ainda hoje, dizem respeito à obtenção da certeza do conhecimento e à questão do método de justificação: é necessário que o conhecimento científico esteja fundamentado. Concebe-se, desde os gregos antigos, a episthéme como um conhecimento que necessariamente "dá razão" às suas afirmações e, portanto, suas proposições devem estar alicerçadas em bases sólidas.

Escreveu Habermas (1982, p. 25): “quisesse alguém reconstruir o debate filosófico dos tempos modernos na forma de um júri, esse teria que ser convocado para decidir sobre a seguinte questão: como é possível adquirir um conhecimento digno de crédito?" Esta questão, proposta de outra maneira, pode ser expressa nos termos seguintes: como podemos nos certificar de que o conhecimento que detemos é verdadeiro? Se tal possibilidade existe, cabe-nos indagar a respeito dos requisitos que devem ser atendidos para que o conhecimento obtido seja reputado como verdadeiro. Ou seja, existem critérios legítimos de cientificidade capazes de garantir a certeza do conhecimento?

O estabelecimento dos critérios de cientificidade, em princípio capazes de validar o conhecimento produzido, há séculos, tem sido motivo de preocupação de inúmeros pesquisadores e filósofos. A metodologia tradicional propõe que tais critérios sejam obtidos a partir da proposição de um método científico e da definição do objeto de pesquisa. Nas últimas décadas, especialmente, este procedimento tem sido amplamente questionado.

\section{A DESCONSTRUÇÃO DA IDEIA DE MÉTODO CIENTÍFICO}

Aqueles que acompanharam o debate filosófico acerca dos fundamentos da ciência durante o século XX, viram dissolver o anelo de muitos que pleitearam por um método capaz de permitir o encontro de uma episthéme, segundo os moldes clássicos. A leitura de alguns textos de Karl Popper, Thomas Kuhn e Paul Feyerabend, ao lado de As palavras e as coisas e A arqueologia do saber, de Michel Foucault, dentre outros, nos permite esclarecer melhor este episódio.

O tratamento dado pelos filósofos da ciência pós-empirista do século XX à questão do método, caracterizou-se pela ênfase na identificação do método proposto como científico e nas teorias propostas. Por esta via, procurou-se investigar a possibilidade de estruturação do conhecimento sobre um alicerce sólido, para obtenção de um conhecimento apodíctico, tendo como horizonte os saberes arrolados pela ciência moderna nos últimos séculos. 
Uma outra perspectiva de trabalho foi proposta por aqueles que, por uma razão ou outra, abandonaram a crença de que é possível alcançar a compreensão dos significados dos escritos acadêmicos e oferecer explicações detalhadas sobre as temáticas abordadas, atendo-se apenas à identificação do método, dos procedimentos de pesquisa utilizados, dos objetos, das teorias e dos conceitos construídos. Por este caminho, a tentativa de definição dos objetos, do método e dos procedimentos, não é suficiente, quando se busca o aprofundamento na compreensão. Muitos dos que se identificam com esta vertente são capazes de listar inúmeros elementos influentes, externos às metodologias. Por esta via, procura-se compreender os sentidos dos textos a partir da análise dos discursos. Esta vertente corresponde aos estudos realizados por Michel Foucault (1999 e 2005) e seus seguidores.

As averiguações realizadas no domínio da Filosofia da Ciência durante o século XX partiram de pressupostos e problemas originários dos séculos anteriores, seguindo a tradição do pensamento crítico moderno, cujos subsídios, a exemplo da crítica ao indutivismo, podem ser encontrados em David Hume e Justus Liebig, principalmente. As grandes questões que balizaram, desde longa data, as discussões neste campo, indagam a respeito da existência de uma lógica da descoberta, o que pode ser traduzido pela seguinte pergunta: é possível se criar uma metodologia científica? Além deste, outro questionamento importante diz respeito à possibilidade de reconstituição racional do progresso científico, cuja intenção é saber se as descobertas alcançadas seguiram um desenvolvimento racionalmente compreensível.

Hume (1972) entendeu que o princípio que torna possível a inferência de um fenômeno pelo aparecimento de outro, assim como a observação de que os objetos e eventos familiares estão constantemente ligados, não é a indução, mas sim o costume, ou o hábito. Posição diversa foi defendida por Kant (1994), para quem o conhecimento, embora possa ser iniciado com a experiência, não decorre inteiramente dela. Quando se busca a obtenção do conhecimento, torna-se necessário fazer uso da razão e da experiência, porém a última está subordinada à primeira. Seguindo a mesma linha de pensamento, Laudan (2000, p. 50), afirma que a "[...] insistência de Kant na presença de elementos ideais no conhecimento científico [...]" solapou a perspectiva indutivo-empírica que dominou a metodologia durante o século XVIII. Entretanto, a noção de conhecimento por demais idealista de Kant, embora pretendendo constituir-se como uma síntese entre o racionalismo e o empirismo, revela-se, sobremodo cética, uma vez que propõe que não somos capazes de conhecer os fenômenos tais como eles são, mas apenas a ideia que fazemos deles, devido às limitações próprias da inteligência humana.

De acordo com Laudan (2000, p. 57), Liebig ofereceu “[...] uma crítica incisiva do indutivismo baconiano, sustentando convincentemente que nenhum cientista jamais havia seguido ou jamais poderia seguir os métodos descritos no Novum organum”. Desde Francis Bacon e Isaac Newton, a indução foi concebida como método de descoberta; porém, as posições de Liebig abriram caminho para a concepção da indução, não mais como técnica para produzir leis e teorias, mas como lógica da confirmação.

Durante o século XX, os estudos conduzidos por Karl Popper, Imre Lakatos, Thomas S. Kuhn e Paul Feyerabend, dando prosseguimento a esse antigo debate, conduziram ao enfraquecimento da crença de que, pela via da indução, obtém-se o conhecimento, mormente no domínio das ciências naturais. Pode-se claramente relacionar as posições defendidas pelos pós-empiristas acima referidos à argumentação apresentada por Liebig, ainda no século XIX, e arroladas por Laudan (2000, p. 58), segundo a qual "a descoberta não se submetia a absolutamente nenhuma regra e menos ainda às do método indutivo". Como decorrência, verifica-se a impossibilidade de se "criar uma lógica da descoberta à prova de erros".

Uma famosa frase, atribuída a Popper, é ilustrativa desta concepção, quando em suas apresentações dizia: “sou um professor de 'método científico' mas tenho um problema: não existe método científico". Entretanto, Popper deixava claro que "há algumas regras práticas que podem ser bastante úteis [...]” (FEYERABEND, 1996, p. 96). Posição semelhante pode ser encontrada em Kuhn (2006, 
p. 353), quando afirma "[...] ainda não acredito numa lógica da descoberta, embora pense que se possa falar, não a respeito da lógica, mas das circunstâncias, de modo que iluminem a descoberta".

Popper (1972) entendeu que não existe um método lógico de conceber ideias novas ou de se reconstruir, racionalmente, as fases que conduziram à descoberta. Para ele, toda descoberta "[...] encerra um "elemento irracional" ou "uma intuição criadora" [...] (POPPER, 1972, p. 32). O que Popper tem em vista não é, exatamente, um método de descoberta, ou uma técnica para produzir leis e teorias. Parte do entendimento de que as idéias arriscadas, as antecipações injustificadas, o pensamento especulativo, são os poucos meios de que podemos lançar mão para interpretar a natureza. "Não sabemos: só podemos conjecturar. Nossas conjecturas são orientadas por fé não científica, metafísica (embora biologicamente explicável), em leis, em regularidades que podemos desvelar, descobrir" (POPPER, 1972, p. 306). O que Popper propõe serve mais como um método de prova, que consiste em submeter teorias a testes, com base em inferências dedutivas, ciente de que estas nunca são inteiramente verificáveis ou justificáveis. Como decorrência, a compreensão subjacente às suas próprias proposições, é a de que "nossa ciência não é conhecimento (episteme): ela jamais pode proclamar haver atingido a verdade ou um substituto da verdade, como a probabilidade" (POPPER, 1972, p. 305).

Contrariamente à grande maioria dos metodólogos, Popper sustenta (inclusive para as ciências sociais) que o desenvolvimento das etapas da pesquisa científica inicia-se com a identificação do problema. "O conhecimento não começa de percepções ou observações ou de coleção de fatos ou números, porém, começa, mais propriamente, de problemas (POPPER, 1978, p. 14). As etapas seguintes da pesquisa referem-se à proposição e ao teste de hipóteses. Ao invés de procurar provar a veracidade das hipóteses, pretende-se, antes, refutá-las. De fato, Popper não afirmou o estabelecimento de um método científico único, ou uma metodologia de pesquisa científica capaz de oportunizar descobertas científicas, mas, sim, a possibilidade de aplicação de um método de prova, em princípio, útil tanto para os estudos sobre a natureza como para as pesquisas que tratam da sociedade, da política, da economia etc.

Entretanto, a concepção de ciência idealizada por Popper (1972 e 1978), fundamentada na crítica ao indutivismo e com base em conjecturas e refutações, apesar de constituir-se em um avanço significativo da própria concepção racionalista de ciência, não apresentou respostas suficientes às questões colocadas pelos historiadores da ciência, com respeito à dinâmica do progresso do conhecimento. Diversas teorias tidas como refutadas no passado, provaram, posteriormente, sua utilidade, e foram reabilitadas, como se pode perceber nos levantamentos de Kuhn (2000), Lakatos (1979) e de Feyerabend (1989). Este último argumenta que alguns dos mais notórios falseamentos ocorridos são claramente irracionais, ou são apoiados em princípios de racionalidade externos ao racionalismo crítico. Feyerabend (1989, p. 278) alega, ainda, que os princípios do racionalismo crítico "[...] proporcionam inadequada explicação do passado desenvolvimento da ciência [...] pois esta é muito mais 'fugidia' e 'irracional' do que sua imagem metodológica”.

A partir da publicação de A Estrutura das Revoluções Científicas por Thomas S. Kuhn, em 1962, espalhou-se uma onda de relativismo que influenciou profundamente estudos subsequentes no campo da Filosofia da Ciência. A ausência de critérios objetivos de cientificidade - característica da posição relativista - tem sido visualizada na obra de Kuhn (2000), quando propõe uma discussão acerca das teorias científicas sob uma perspectiva histórica e sociológica, relacionando o conhecimento científico à comunidade que o produziu. A dimensão sociológica do paradigma - aspecto que foi ressaltado por Margaret Masterman (1979) - pode ser verificada no seu caráter consensual, pois Kuhn (2000) o concebe como realização científica universalmente reconhecida. Assim compreendido, para este último, a eleição de um paradigma não decorre da aplicação de critérios objetivos de cientificidade, mas das escolhas feitas pela comunidade de pesquisadores. Tais critérios são, portanto, subjetivos, de tal sorte que podemos inferir que Kuhn compreendeu o progresso do conhecimento como processo irracional e não-indutivo. 
A compreensão de que os aspectos históricos e sociológicos são fundamentais na abordagem de Thomas Kuhn torna-se ainda mais evidente quando, em uma de suas últimas obras, O caminho desde A Estrutura, realiza uma crítica sobre a crença na existência de um método científico. Kuhn explica que a instrução oferecida à sua geração induziu todos a acreditarem em um conjunto tradicional de crenças, segundo a qual a ciência provém de fatos objetivos dados pela observação, acessíveis e indubitáveis a todos os observadores humanos normalmente equipados, ainda que, para isso, tenha sido necessária a invenção de elaborados instrumentos de observação. A velha imagem do que constituía a ciência rezava que esses fatos "[...] são anteriores às leis e teorias científicas para as quais fornecem o fundamento e que, por sua vez, constituem a base para explicações de fenômenos naturais" (KUHN, 2006, p. 135). Para a concretização da descoberta de leis e teorias que permitissem o oferecimento de explicações, tornava-se necessária a interpretação dos fatos, verificando-se, contudo, que, por se tratar de um processo humano, os resultados alcançados nessa etapa apresentavam variações segundo os observadores e de acordo como seus intérpretes. Estes procedimentos, de maneira geral, até então, constituíram algo denominado método científico. Às tentativas de aprimoramento da compreensão do método científico, sobrevieram profundas dificuldades, que conduziram alguns filósofos insatisfeitos à realização de observações a respeito da vida científica e da história. Tais dificuldades, que, com frequência, eram suficientes para afetar pontos cruciais da interpretação, referem-se, especialmente, ao fato de que os resultados de observações obtidos diferiam de observador para observador, mesmo quando se tratava dos mesmos fenômenos. As divergências de interpretação surgidas requeriam a revisão das concepções a respeito daquilo que estava sendo observado. Apesar dos esforços, sempre persistiram desacordos sobre se alguma lei ou teoria particular deveria ser aceita. Além disso, os fatos observáveis não se mostravam independentes das crenças e das teorias existentes. "Produzi-los exigia uma aparelhagem, ela própria dependente de teoria, na maioria das vezes dependente da teoria que os experimentos iriam, supostamente, testar" (KUHN, 2006, p. 135).

Por conta disso, fatores pessoais, de origem histórica e determinados aspectos sociológicos passaram a ser interpretados pelos filósofos da ciência com inclinações históricas, como promotores das diferenças nos resultados, uma vez que a observação e a experimentação não eram suficientes para levar indivíduos diferentes às mesmas conclusões.

À semelhança de Popper (1972), Kuhn (2000, 2006), Paul Feyerabend (1989) e Imre Lakatos (1979) também descrevem o progresso científico como processo não indutivo. Este último procurou sofisticar as ideias de Popper, alegando que a história da ciência é a história dos programas de pesquisa, mais do que a história das teorias. A concepção do falseacionismo sofisticado, defendida por Lakatos (1979), pressupõe a compreensão de que as teorias não são avaliadas individualmente, mas em série, ou seja, como sucessão de teorias, ou, em uma terminologia que comporta sentido similar, como programas de pesquisa. Lakatos $(1979$, p. 161) sustenta que "[...] os principais problemas da lógica da descoberta só podem ser satisfatoriamente discutidos na estrutura de uma metodologia dos programas de pesquisa".

Se Kuhn (2000) utilizou a noção de paradigma para discernir a ciência da não-ciência, Lakatos (1979) propôs que procedimento semelhante deve ser realizado com base nos programas de pesquisa, considerando a produção de fatos novos como critério empírico para julgá-los como satisfatórios. Tendo isto em vista, a comparação de programas de pesquisa rivais pode ser realizada à medida que eles estejam progredindo ou degenerando, pois se subentende que os programas degenerescentes cederão lugar aos programas progressistas.

Averiguações concernentes ao suposto método científico têm sido empreendidas, em anos recentes, por diversos autores. Um tratamento peculiar às metodologias foi desenvolvido por Feyerabend (1989), para quem o progresso científico alcançado decorre, em maior medida, do acaso, preconceito, vaidade e paixão - em oposição à razão - do que de regras metodológicas. Provavelmente, a argumentação mais detalhada contra a ideia de uma via racional de progresso científico tenha sido 
apresentada por ele. A grande ciência, em sua visão "[...] é uma aventura intelectual que não conhece limites e não reconhece regras, nem mesmo as regras da lógica" (FEYERABEND, 1989, p. 286).

Feyerabend (1989) condena a ingênua e infantil confiança na ciência, pois a vê com aparência desagradável, como um grande negócio, associado a uma ideologia própria. As leis científicas, para ele, não são definitivas e irrevogáveis, e contêm aspectos incorretos e, às vezes, inteiramente falsos. A ciência tem apresentado, muitas vezes, resultados indignos de confiança, o que desfigura sua imagem de empreendimento superior às outras formas de conhecimento, o que permite aproximá-la do mito. Assim, dificilmente se pode distingui-la da astrologia, da religião ou da mágica. Em sua leitura, a posição requerida pela ciência face às demais formas de conhecimento, ou seja, seu status, resulta, em grande parte, da habilidade que os cientistas desenvolveram de transformar suas opiniões em verdades (FEYERABEND, 1996). À vista de suas críticas, que podem resultar na afirmação cabível de que o empreendimento científico deve ser abandonado, Feyerabend sugere o anarquismo metodológico, com base na asserção de que o único princípio que não inibe o progresso do conhecimento é o "vale tudo", deixando claro, porém, que seu objetivo "[...] não é o de substituir um conjunto de regras por outro conjunto do mesmo tipo: meu objetivo é, antes, o de convencer o leitor de que todas as metodologias, inclusive as mais óbvias, têm limitações" (FEYERABEND, 1989, p. 43).

Um ponto de discordância entre Feyerabend e Popper diz respeito ao desencadeamento do processo investigativo. Se Popper $(1972,1978)$ entende que a pesquisa inicia-se com um problema, Feyerabend (1989) não entende assim. Para este último, a identificação de um problema não corresponde ao modo pelo qual se desenvolvem as crianças, pois estas "usam palavras, combinam essas palavras, com elas brincam, até que apreendem um significado que se havia mantido para além de seu alcance". Desta forma, "a atividade lúdica inicial é requisito básico do ato final de compreensão. Não há razão para supor que esse mecanismo deixe de agir na pessoa adulta.” (FEYERABEND, 1989, p. 32).

O que Feyerabend (1989) tem em vista é a percepção de que o desenvolvimento das ideias, das práticas, das teorias etc, não ocorre a partir da identificação de um problema, porém, no desempenho de uma atividade anterior à própria formulação do problema, ou seja, em algo parecido com o jogo.

Sob a perspectiva de Feyerabend (1989), o esforço empreendido por Lakatos (1979), no sentido de desenvolver uma metodologia racionalista, esbarrou na dificuldade de estabelecer critérios utilizáveis na comparação dos programas de pesquisas - nunca se sabe quando um programa de pesquisa degenerescente deve ceder lugar a outro, tido como progressista. Um dos argumentos de Feyerabend (1989) é o de que não se pode criticar racionalmente um cientista que se apega a um programa de pesquisa em degenerescência, pois não há meio racional de mostrar que são desarrazoadas suas ações. Este mesmo programa de pesquisa poderá recuperar-se e atingir, no futuro, um imprevisto esplendor. A metodologia pode ser útil na avaliação histórica em que o pesquisador toma decisões, mas não contém regras que possam indicar ações futuras.

Alan Chalmers (1993, p. 120), quando interpreta Feyerabend, conclui que "por causa da incerteza do resultado de tentativas futuras de desenvolver e testar um programa de pesquisas, não se pode nunca dizer, de programa algum, que ele degenerou para além de toda a esperança". Por conseguinte, é aceitável afirmar que não apenas as possibilidades de se estruturar uma metodologia de pesquisa científica mostram-se diminuídas, como também se verifica um enfraquecimento na fundamentação das concepções racionalistas.

Existem diversos pontos comuns entre as abordagens propostas por Feyerabend (1989) e Lakatos (1979). Além do já citado acordo com respeito à percepção de que critérios irracionais apoiaram alguns dos falseamentos mais notórios, Feyerabend (1989) concorda com Lakatos (1979) na defesa de uma metodologia que conceda trânsito livre para novas ideias. De igual forma, a percepção de que a evolução da teoria no decurso de longos períodos de tempo importa mais do que sua configuração em um dado momento particular, é um ponto coincidente entre os dois auto- 
res. Concordam, igualmente, que os padrões metodológicos não são imunes à crítica e devem ser examinados e aprimorados recorrendo-se a dados históricos. Estes pontos de concordância, afirma Feyerabend (1989), isentam Lakatos da maioria das objeções apresentadas ao racionalismo crítico, em Contra o Método.

A metodologia dos programas de pesquisa de Lakatos, conforme Feyerabend (1989), não inclui a exigência de abandono de teorias desprovidas de suporte empírico (diferentemente do indutivismo e do falseacionismo), o que confere grande margem de liberdade à empresa da pesquisa. Isto porque, diante dos argumentos que propugnam a necessidade de padrões mais liberais, a especificação das condições em que um programa de pesquisa deve ser rejeitado se torna impossível. Até mesmo a identificação do momento em que continuar a apoiar determinado programa degenerescente constitui ato irracional, se torna impraticável. Segue daí que Feyerabend (1989, p. 290) não vê diferença racionalmente perceptível entre sua posição e a de Lakatos (1979).

Os padrões (entendidos como critérios de racionalidade) escolhidos por Lakatos (1979), não permitem eliminar teorias incompatíveis com enunciados básicos aceitos e não encerram juízos gerais concernentes à racionalidade ou irracionalidade de uma via de ação. Feyerabend (1989, p. 302) observa que, na forma em que propôs Lakatos (1979), "o programa de pesquisa passa a ser abandonado não porque se levantem contra ele argumentos fundados nos padrões, mas porque seus adeptos se vêem impossibilitados de prosseguir". Para Feyerabend, a filosofia de Lakatos pode ser vista como um anarquismo disfarçado, pois entende que não há diferença "racionalmente" perceptível entre as posições de ambos e que a aceitação pacífica da metodologia dos programas de pesquisa não ocasiona qualquer dificuldade para o anarquista metodológico.

Ao comparar as posições de Lakatos e Kuhn às suas, Feyerabend (1989) verifica que o primeiro saiu em busca de uma explicação racional para o progresso do conhecimento, mas que, aparentemente, nesta busca não obteve êxito. Quanto ao mais, neste particular, suas posições são semelhantes às de Kuhn, entendendo que o processo de mudança é irracional.

A desistência de Feyerabend, talvez precipitada, de procurar uma via racional para o desenvolvimento científico revela-se, antes, uma decisão pessoal que não contém nenhum valor prescritivo, pois a ineficiência demonstrada pelos modelos propostos não implica na impossibilidade de surgimento de critérios que possam orientar o empreendimento da pesquisa.

Se, por um lado, a tradição cultural em que fomos instruídos nos obriga a identificar como exagero a consideração de Paul Feyerabend (1989), quando supôs no mesmo nível os saberes acadêmicos (com pretensões científicas) e as práticas de feitiçaria, bruxaria e astrologia, etc, por outro, não há dúvida de que suas posições contribuem significativamente na peleja contra equivocadas concepções de ciência e de método científico, como também para o combate à ideologia da ciência. Na visão de Chalmers (1993, p. 214), "essa ideologia envolve o uso do conceito dúbio de ciência e o conceito igualmente dúbio de verdade, freqüentemente associado a ele, geralmente na defesa de posições conservadoras".

Malgrado as diferenças que podem ser verificadas entre as concepções de Popper, Lakatos, Kuhn e Feyerabend, e apesar de seus atritos e incompreensões, observamos que são inúmeras as regularidades identificáveis nos seus discursos filosóficos, no que concerne à questão do método. Verificamos que, do intenso debate por eles promovido, sobressaíram alguns esclarecimentos sobremaneira úteis para a elucidação de determinados problemas reincidentes que envolvem as disciplinas acadêmicas, inclusive no que reporta à Geografia.

A consciência de que, apesar de todo o rigor aplicado às pesquisas, os saberes obtidos continuam nuançados de incerteza e erro, e de que "o velho ideal científico da episteme - do conhecimento absolutamente certo, demonstrável - mostrou não passar de um "ídolo", como escreveu Popper (1972, p. 30), é uma das principais consequências dessa reflexão. A percepção de que não podemos justificar racionalmente nossas teorias destaca-se entre as decorrências do raciocínio dos pós-empiristas. Se o que julgamos haver aprendido ao fim de exaustivas pesquisas de campo, análises 
e discussões, não pode ser tomado como conhecimento seguro (pois também resulta de suposições especulativas e opiniões pessoais), a referência a uma epistemologia, como investigação sobre os procedimentos de produção do conhecimento científico, precisa ser revista.

Se declinamos da crença na eficiência de nossas metodologias e se admitimos que não existem critérios racionais legítimos de cientificidade (inclusive no que diz respeito às ciências naturais), se não existem regras que possibilitem a obtenção do conhecimento seguro, por que ainda fazemos uso da expressão "metodologia científica"?

Uma outra decorrência diz respeito ao fato de que os avanços promovidos por Kuhn, Popper e seus seguidores, na compreensão da questão do método, alteram nosso entendimento acerca do positivismo, que, a nosso ver, não pode mais ser tomado apenas como a aplicação do método das ciências naturais nos estudos conduzidos no âmbito das ciências sociais. Se a indução não pode ser apontada como o método das ciências naturais, e mais ainda, se não há um método, ou uma lógica da descoberta, claramente definida, como dizer que a aplicação deste suposto método nas ciências sociais corresponde ao positivismo? Talvez seja mais conveniente afirmar-se que o positivismo relaciona-se à equivocada aplicação dos pressupostos teóricos com os quais se pratica a pesquisa no campo da Física, Química, Biologia, etc, aos estudos humanos e sociais (nos domínios correspondentes à Sociologia, Economia, Geografia, etc), e, assim, aproximar a postura positivista daqueles que crêem na existência de uma lógica da descoberta, de um caminho prescrito para se alcançar o conhecimento fundamentado, a episthéme.

Do debate entre os filósofos da ciência pós-empiristas do século XX, destilamos ainda uma outra verificação, relacionada à dificuldade de caracterização da atividade científica, de maneira ampla, capaz de abranger todos os campos do saber, considerando o que acabamos de expor. São abundantes as tentativas de definição do termo ciência, conduzidas por aqueles que reduziram a abrangência desta pergunta, e por isso oferecem respostas com base em termos genéricos. De modo geral, terminam por se mostrar insatisfatórias, ao devolverem a pergunta com um raciocínio circular, ao exemplo de "atividade em que se faz uso do método científico".

À falta de critérios de cientificidade que possam ser aplicados aos diversos campos de pesquisa, resta apenas caracterizar cada campo específico, no que cada um apresenta de científico. Para isso, os adeptos da metodologia tradicional reclamam a exigência da combinação objeto e método em sua caracterização de ciência, opção que nos faz retornar à questão anterior. Mas se se admite a ausência de método característico, e apela-se para a delimitação do objeto, cria-se um outro problema. Este está relacionado à dificuldade de se diferenciar os saberes que dizem respeito a um mesmo objeto. Decorre isto do fato de que os objetos e os fenômenos, com frequência, se mostram imbricados, constituindo-se em um impedimento à delimitação exata dos campos de estudo. Não sendo possível demarcar as fronteiras de forma precisa, como definir cada campo científico específico?

A pesquisa empreendida por Chalmers (1993), no sentido de compreender o que pode caracterizar a ciência, como categoria geral, em relação à qual as áreas do conhecimento possam ser enquadradas como científicas ou não, resultou infrutífera. Sua conclusão leva a crer que "os filósofos não têm recursos que os habilitem a legislar a respeito dos critérios que precisam ser satisfeitos para que uma área do conhecimento seja considerada aceitável ou "científica"” (CHALMERS, 1993, p. 211). A ausência de critérios objetivos, além de impossibilitar a classificação das disciplinas, também inviabiliza a rotulação de pesquisas, artigos, dissertações, teses e livros, de conteúdos diversos, como científicos ou não. Não sabemos claramente o que, a rigor, significa ciência, pois este termo se mostra excessivamente carregado de sentido, e, ao mesmo tempo, vazio. Porém, suspeitamos que a carga ideológica que pesa sobre ele seja a causa de muitas das nossas incompreensões.

Diante da dificuldade de caracterizar como científicos ou não, cada disciplina, área do saber, ou campo do conhecimento, deparamo-nos com a possibilidade de entendê-los, todos, apenas como saberes. Escrito desta maneira, esta afirmação não aparece nos textos de Michel Foucault, mas uma aproximação de sua obra à dos autores revisados anteriormente sugere esta hipótese. 
A arqueologia histórica do saber, de Michel Foucault, diz respeito a uma abordagem que não se debruça exatamente sobre as temáticas abordadas pelos pós-empiristas do século XX, mas, em alguns aspectos, está profundamente relacionada.

Depreende-se, da análise de As palavras e as coisas, que Foucault concebe a existência de figuras epistemológicas, de saberes detentores de critérios de objetividade e sistematicidade, que permitem a definição de algumas áreas como ciências. Entretanto, não estabeleceu tais critérios para nenhuma das ciências empíricas por ele discutidas (linguística, biologia e economia), como também não o fez para as ciências matemáticas e físicas que ele pressupôs (FOUCAULT, 1999).

Foucault (1999) entendeu que o conhecimento relaciona-se ao saber empírico, porém, não considera a possibilidade de obtê-lo nas ciências humanas, em razão da ausência de critérios legítimos de cientificidade; por isso rejeita uma epistemologia das ciências humanas, pois, de alguma maneira, ela corresponde à teoria do conhecimento, ou, à metodologia tradicional, que, para o caso das ciências humanas, se mostra inaplicável.

Com esta visão, Foucault (2005) procura desenvolver e definir a noção de enunciado, entendida como a unidade elementar do discurso, e assim oferecer subsídios para uma compreensão mínima do sentido dos discursos. A noção de enunciado não deve ser confundida com as noções de proposição e de frase. "O enunciado não é, pois, uma unidade elementar que viria somar-se ou misturar-se às unidades descritas pela gramática ou pela lógica. Não pode ser isolado como uma frase, uma proposição ou um ato de formulação [...]” (FOUCAULT, 2005, p. 123). Apesar disso, proposições e frases podem ser consideradas enunciados, desde que seja possível assinalar-se a posição do sujeito. Para este autor, "de maneira geral, parece, pelo menos à primeira vista, que o sujeito do enunciado é precisamente aquele que produziu seus diferentes elementos com uma intenção de significação" (FOUCAULT, 2005, p. 104).

A partir da noção de enunciado, que se mostra fundamental, é possível compreender-se a noção de discurso como sendo um "[...] conjunto de enunciados que se apóia em um mesmo sistema de formação [...]", ou seja, na mesma formação discursiva (FOUCAULT, 2005, p. 122). Se no enunciado já se faz presente a posição do sujeito, no discurso, mais claramente, esta verificação é possível.

Foucault (1999 e 2005) se recusa a tratar da epistemologia das ciências humanas, e o faz na crença de que alguma epistemologia é possível para determinados campos do saber. De fato, em As palavras e as coisas, Foucault não discute epistemologia. Em lugar disso, sua preocupação volta-se para uma arqueologia do saber. Entretanto, a tarefa de fazer a crítica da epistemologia não foi levada adiante por Foucault, mas coube à escola de pensamento que, começando pela física, tida como padrão para as demais disciplinas acadêmicas, corroeu a noção de ciência por dentro; a filosofia da ciência, na linha de Popper, Lakatos, Kuhn e Feyerabend, tratou disso.

A teoria da ciência de Popper, Kuhn e, especialmente, de Paul Feyerabend, foi mais eficaz do que a argumentação de Michel Foucault na crítica à ideologia do cientificismo. Popper, especialmente porque atacou a crença na indução como método característico da atividade "científica". Kuhn porque propôs que critérios não objetivos orientam a escolha de seus pretensos paradigmas. Feyerabend (1989 e 1996) quando nos fez crer que todas as metodologias até hoje elaboradas têm limitações e que as supostas verdades propaladas pelos cientistas estão carregadas de suas opiniões. Contudo, Foucault (1999 e 2005) adiantou-se àqueles quando sugeriu a análise de discursos e a arqueologia histórica como instrumentos de compreensão dos saberes, especialmente no domínio das humanidades.

A filosofia da ciência (de Popper, Lakatos, Kuhn e Feyerabend), vista como negação da metodologia das ciências naturais, e a arqueologia histórica do saber de Michel Foucault (tomada à maneira de uma negação da epistemologia das ciências humanas), dispostas lado a lado, jungidas, oferecem, em função de suas coincidências e complementaridades, subsídios importantes para a desconstrução da ideia de que um método científico preside os diversos campos do saber. 
O encontro destas duas abordagens nos permite compreender, inclusive, alguns importantes problemas relacionados à Geografia, como disciplina acadêmica e como saber moderno. Todavia, existem outras tradições importantes neste terreno, a exemplo da teoria crítica da escola de Frankfurt e da análise dos sistemas mundiais, de Immanuel Wallerstein. Este último contribuiu, sobretudo, quando tratou dos aspectos ideológicos relacionados ao surgimento das ciências sociais, no contexto do liberalismo reinante nos séculos XVIII e XIX. Além disso, há que se considerar a contribuição endógena dos autores que empreenderam análises circunscritas aos seus campos originais de discussão. No caso específico da Geografia, aceitamos como especialmente relevantes as contribuições de Horácio Capel, Yves Lacoste, Milton Santos e R. J. Johnston.

Podemos ainda avaliar a posição de Kuhn (2006), que aceita bem a ideia de que as ciências sociais caracterizam-se por seus procedimentos hermenêuticos, interpretativos, ao contrário das ciências naturais, que embora possam requerer uma base hermenêutica, não podem ser assim caracterizadas, pois nelas ocorre, de algum modo, uma pesquisa normal, solucionadora de quebra-cabeças. Assim compreendidas, as ciências sociais tendem para a especulação filosófica, ou, para a opinião, fazendo-se uso de uma terminologia bem ao gosto de Feyerabend.

\section{GEOGRAFIA ENQUANTO SABER MODERNO}

Um esforço no sentido de constituição de uma arqueologia da Geografia, à maneira empreendida por Foucault (1999) para o conjunto das ciências humanas, aparentemente não pode ser realizado de forma independente, isto é, sem levar em conta as demais disciplinas que tratam do quadro social, econômico, político e da natureza.

Quando Foucault (1999) discute o surgimento da Economia, da Lingüística e da Biologia (esta última, em substituição à História Natural), na passagem para o século XIX, não trata explicitamente da Geografia; sequer faz referência a ela, ou mesmo à Ecologia (cujas temáticas, em muitos aspectos, correspondem às temáticas abordadas pelos geógrafos), que aparece delineada como campo de estudos no final do século XIX, contemporânea ao surgimento da Geografia moderna.

No quadro traçado por Foucault (1999), não podem ser percebidas positividades relacionadas às demais "ciências humanas". Estas somente podem ser encontradas nos estudos da vida, da linguagem e do trabalho, ou seja, nas ciências empíricas. O domínio das ciências humanas não foi previamente delineado, mas Foucault (1999, p. 486) sugere que estas se encontram posicionadas nas vizinhanças, nas fronteiras e "[...] em toda a extensão dessas ciências em que se trata da vida, do trabalho e da linguagem".

Porém, o que ficou subentendido pela crítica realizada por Foucault (1999 e 2005) às ciências humanas, aquilo que os geógrafos positivistas (com freqüência, inconscientes) não comentaram, relaciona-se ao que Habermas (2000), denominou de "desmascaramento das ciências humanas". Significa que não existe a possibilidade de estabelecimento de um estatuto epistemológico próprio para a Geografia e, igualmente, que não temos elementos suficientes para caracterizá-la como ciência. Esta posição, porém, não se refere apenas à Geografia, mas ao conjunto de saberes relacionados às ciências humanas.

Inútil, pois, dizer que as "ciências humanas" são falsas ciências; simplesmente não são ciências; a configuração que define sua positividade e as enraíza na epistémê moderna coloca-as, ao mesmo tempo, fora da situação de serem ciências [...] A cultura ocidental constituiu, sob o nome de homem, um ser que, por um único e mesmo jogo de razões, deve ser domínio positivo do saber e não pode ser objeto de ciência. (FOUCAULT, 1999, p. 507).

Quando Foucault (1999) precisou que, sobre as humanidades não cabe uma análise epistemológica, mas sim uma arqueologia, em razão da ausência de critérios de cientificidade que poderiam tornar possível uma investigação sobre os procedimentos de produção do conhecimento, resultou 
daí, apenas, o caráter que as qualifica enquanto saberes. Se Foucault estiver certo, a Geografia corresponde a um saber, ou a um conjunto de saberes.

Depurada pela filosofia da ciência do século XX e pela arqueologia histórica do saber de Foucault, a Geografia resta como um saber, junto a outros saberes relativos ao homem, de maneira que não inovamos se, em lugar da expressão "ciência geográfica", fizermos uso da expressão "discursos geográficos".

Mesmo reconhecendo a importância do que foi escrito por Foucault, ainda se alude, entre os geógrafos, a uma suposta ciência geográfica. Sustentamos que é esta uma postura compatível com a concepção tradicional de ciência (senão positivista), e que também desconsidera as discussões promovidas por Popper e pelos que o seguiram, no âmbito da filosofia da ciência.

\section{A QUESTÃO DO MÉTODO NO PENSAMENTO GEOGRÁFICO}

Apesar do fato de que "ao desenvolverem suas análises, os geógrafos humanos procuravam crescentemente uma identidade clara para si próprios dentro das ciências sociais", como afirmou Johnston (1986, p. 132), não deparamos com um método consensual adotado como instrumento condutor da pesquisa no domínio da Geografia. Alcançamos esta constatação após averiguarmos as posições de alguns dos importantes textos que abordam, ainda que indiretamente, a temática do método nesse domínio do conhecimento, partindo do primeiro capítulo do livro Princípios de Geografia Humana, denominado "Vista de Conjunto", de Paul Vidal de La Blache, encontramos uma referência importante.

Como um ramo do velho tronco da Geografia e expressão do desenvolvimento das idéias, Vidal de La Blache (1954, p. 27) apresenta a Geografia Humana, que a seu ver traz "[...] uma nova concepção das relações entre a Terra e o Homem [...]”. Mais adiante, fundamentando-se em Ratzel, La Blache (1954, p. 30) sugere que "os factos de Geografia humana ligam-se a um conjunto terrestre e apenas por este são explicáveis; relacionam-se com o meio que, em cada lugar da Terra, resulta da combinação das condições físicas". Em outros trechos de Princípios de Geografia Humana, La Blache, seguindo pela mesma linha, faz referência ao "estudo das relações da Terra e do homem", como característicos da nova disciplina. Nesse texto, que constitui para nós uma das obras mais representativas da Geografia do início do século XX, na tarefa de determinar em que medida a Terra está ocupada pelos homens, de verificar a extensão das desigualdades e identificar as anomalias, afirma que,

O geógrafo não pode contentar-se com os números publicados nas estatísticas oficiais. É necessário que lhes junte os dados que diversas fontes the podem fornecer [...] Todas as partes da superfície terrestre devem ser consideradas [...] Só o conjunto, precisamente pelas diferenças, contrastes e anomalias que permite descobrir, assume pleno significado. (VIDAL DE LA BLACHE, 1954, p. 49).

Em outro trecho, mantendo a mesma perspectiva, escreve que "atualmente, numa vista de conjunto, verificamos um número aproximado que representa o total dos homens tão desigualmente distribuídos na superfície terrestre" (VIDAL DE LA BLACHE, 1954, p. 58). Se, de forma predominante, o texto apresenta-se como uma descrição, a preocupação com a percepção do conjunto (de um povoamento vegetal, de uma região ou da superfície terrestre) pode ser facilmente verificada. "Os factos de Geografia humana ligam-se a um conjunto terrestre e apenas por este são explicáveis [...]” (VIDAL DE LA BLACHE, 1954, p. 30).

Wooldrigde \& Gordon East (1967, p. 14) expressam opinião semelhante, ao assinalar que a Geografia “[...] funde os resultados, se não os métodos, de um sem-número de outras matérias", embora o texto que tomamos por base faça referência apenas à produção acadêmica dos geógrafos na Grã-Bretanha, até meados do século XX. Em razão disso, estes autores tratam da Geografia como uma disciplina sinóptica, e destacam, na produção dos geógrafos, uma preocupação com a 
totalidade. Como adiante será abordado, também os proponentes da abordagem da complexidade manifestam atenção para com uma visão de totalidade.

Os diversos fios de sua trama passam despercebidos, no plano do imediato e óbvio. Mas a trama existe, apesar disso, e o todo é maior do que a soma das partes, cabendo realizar um esforço no sentido de enxergá-lo em sua totalidade. A necessidade atual de integração, nos campos do saber humano, que divergem e se multiplicam, é urgentemente apregoada. A Geografia se propõe realizar tal integração [...] (WOOLDRIDGE \& GORDON EAST, 1967, p. 184).

Para os autores citados, a verdadeira pretensão do geógrafo é a de "ver as coisas em conjunto", particularidade que os diferencia dos demais pesquisadores, que "escolhem estudar apenas um aspecto dos homens e coisas deste mundo" (WOOLDRIDGE \& GORDON EAST, 1967, p. 186). Capel (1983) oferta a informação de que a concepção de Geografia, enquanto ciência integradora de fenômenos físicos e humanos, concorreu grandemente para a institucionalização universitária desta disciplina a partir de 1880, na Grã-Bretanha.

Pierre George (1978, p. 07-08) sugeriu que o desempenho das atividades de geógrafo "[...] implica um processo de pensamento específico, que parte da descrição para chegar à explicação, em três termos principais: observação analítica, detecção das correlações, busca das relações de causalidade", e propôs o termo "heterogeneidade metodológica", para definir a atitude do geógrafo no desempenho de suas pesquisas, em razão da necessidade de atentar, simultaneamente, tanto para os aspectos humanos, como para os naturais. Assim, entendeu que a heterogeneidade metodológica é característica da Geografia, em razão de sua proximidade com outros campos do saber, a exemplo da Biologia, Geologia, Sociologia, Economia, Psicologia Social etc, o que, de certa maneira, é responsável pela constante procura pela unidade disciplinar.

Esta unidade não pode ser metodológica: a pesquisa geográfica recorre sucessiva ou simultaneamente aos métodos de cada uma das ciências de que se vale para chegar ao conhecimento analítico dos dados incluídos nas combinações que constituem o objeto de seus estudos fragmentários ou globais. (GEORGE, 1978, p. 8-9).

À coleta de dados e à determinação das formas e intensidades das relações entre os dados, George (1978) atribui um caráter de centralidade na pesquisa. No trecho transcrito abaixo, destacamos sua orientação com vistas à apreensão do "todo geográfico".

A coleta de dados atrai o geógrafo para o campo - e para os quadros metodológicos das ciências de análise que dizem respeito ao meio natural e aos fatos humanos. Vê-se ela compelida a assumir as funções do geólogo, do petrógrafo, do pedólogo, do botânico, do climatólogo, do hidrólogo, assim como as do demógrafo, do etnólogo, do sociólogo, do agrônomo, do economista, do urbanista... e isso, toda vez que aborda o todo geográfico. Se não for simultaneamente um historiador, ficará privado totalmente da retrospecção no domínio dos fatos humanos. (GEORGE, 1978, p. 9).

A nosso ver, a adoção da expressão "heterogeneidade metodológica" se mostra inadequada, se compreendemos método no sentido utilizado pelos filósofos da ciência pós-empiristas, ou seja, como lógica da descoberta, ou como caminhamento que conduz ao conhecimento científico. Por esta razão, a proposição de que os geógrafos adotam, desde longa data, uma diversidade de procedimentos de pesquisa, fato que, embora evidente, não distingue a Geografia dos demais campos do saber, traduz melhor a nossa compreensão sobre este assunto.

De acordo com Lacoste (1995, p. 18), “o raciocínio geográfico consiste em articular os diferentes níveis de análise em função da ação empreendida e de levar em consideração as interações dos conjuntos espaciais concernentes". Dessa forma, o saber geográfico relaciona-se à apreciação de uma grande diversidade de fenômenos espaciais. A característica epistemológica maior da 
Geografia, em sua visão, é combinar metodologicamente, em função de práticas específicas, os múltiplos elementos do conhecimento produzidos por ciências cada vez mais especializadas ou por outros saberes.

O próprio Lacoste (1981, p. 222) apontou que muitos geógrafos reconhecem que, “[...] por vezes 'a geografia não pode definir-se nem por seu objeto nem por seus métodos, mas antes, por seu ponto de vista", e contentam-se em afirmar que "a geografia é a ciência de síntese".

Cremos que existem muitos indícios que nos permitem apontar uma tendência, qual seja, a de que os discursos geográficos podem ser caracterizados por uma perspectiva sintética, pela vista do conjunto. Neles podemos identificar o desejo de descrever, representar e traduzir as interações que ocorrem no todo geográfico, como também o próprio todo geográfico, este um compósito que inclui os inúmeros elementos da natureza, da sociedade, da política, da economia e os eventos representativos da história, mesmo que este anseio seja tomado apenas como uma meta, cujo cumprimento dificilmente é atingido.

Apenas para tomarmos um exemplo, não é para a apreensão do conjunto das interações que ocorrem entre os eventos; do todo social, econômico e cultural, que chama a atenção David Harvey (1996) quando se propõe discutir o processo de mudança cultural no capitalismo tardio em "Condição pós-moderna: uma pesquisa sobre a origem da mudança cultural”? Assim, observamos que há evidências de que inúmeros discursos geográficos procuram abarcar o todo, e o fazem a partir da consideração das categorias de análise que, de alguma forma, traduzem este anseio.

Se, conforme afirmou Cássio Eduardo Viana Hissa (2002, p. 75), "a recusa à divisão e a pretensão de "querer reunir tudo" caracterizam a geografia", podemos, sim, no nível das regularidades discursivas, afirmar que a intenção de oferecer explicações com base em uma "visão de conjunto", ou que contemplem o "todo geográfico", caracteriza alguns dos discursos geográficos estudados.

Contudo, verificamos também que alguns dos renomados teóricos que buscaram avançar no conhecimento a respeito das temáticas de base da Geografia, durante as últimas décadas, aparentemente, não se conscientizaram a respeito do corolário das avaliações críticas oferecidas pelo grupo de filósofos da ciência pós-empiristas do século XX, que tornaram sem sentido a caracterização de uma ciência geográfica a partir do estabelecimento de critérios que objetivam a padronização de um método científico.

Assim se pode explicar porque Yves Lacoste se queixa da carência de debate epistemológico entre os geógrafos, na crença de que os geólogos, os climatologistas, os botânicos, os demógrafos, os economistas e os sociólogos, "[...] de cujos trabalhos a geografia se utiliza em parte, desenvolveram um método e um instrumental conceptual que são específicos de uma ciência particular, cujos objetivos não são os da geografia" (LACOSTE, 1981, p. 227). Lacoste (1981) pressupôs que as disciplinas por ele referidas, detêm sofisticados métodos e instrumentos conceituais, o que está longe de constituir uma verdade. O faz, porém, desconsiderando as dúvidas levantadas por Popper (1972), Kuhn (2000 e 2006) e Feyerabend (1989) acerca da episthéme clássica, do conhecimento seguro.

A revisão realizada por R. J. Johnston (1986), presta-se bem como indicativo das dificuldades enfrentadas pelos geógrafos quando tentaram aplicar em seus estudos, as práticas preconizadas e difundidas pelos positivistas lógicos, que obtiveram maior repercussão no imediato pós II guerra mundial. A pressuposição de que a adoção dos procedimentos de investigação, conformados à maneira de um método científico (largamente aceita nas décadas de 1950 e 1960 nos Estados Unidos e na Grã-Bretanha), possibilitaria o desenvolvimento de supostas leis geográficas, não encontrou correspondência nos fatos, embora esta não tenha sido uma conclusão unânime.

Sob a perspectiva que adotamos, não vemos possibilidade de distinguir, ou sequer de caracterizar, os saberes concernentes ao geográfico, a partir de uma verificação do método. No máximo conseguimos observar, em determinadas épocas, a preeminência de uma ou outra vertente de interpretação, ao sabor das influências das diversas correntes filosóficas e dos movimentos políticos. Como exemplo, podemos apontar o fato de que, nas duas últimas décadas, pelo menos entre os 
geógrafos brasileiros, predominou (embora haja discordâncias) a aceitação do espaço como objeto de estudo de sua disciplina, em grande parte, devido à influência de Milton Santos.

Verificamos sim, que, em certa medida, em determinadas épocas, alguns geógrafos entraram em acordo relativamente às temáticas de estudo e aos problemas eleitos como prioritários, mesmo sem haver consenso a respeito dos procedimentos de pesquisa e do objeto de estudo.

Por outra via, o que poderemos dizer a respeito dos discursos geográficos erigidos supostamente a partir do método dialético? Se não pretendemos desmerecer o valor interpretativo que lhes é concernente, não temos outra alternativa senão entendê-los como aplicação das filosofias dialéticas na Geografia. As abordagens dialéticas ainda não lograram a aplicação de um método autêntico e exitoso; da mesma forma, também não foram capazes de sugerir procedimentos de pesquisa específicos. O pensamento dialético fundamenta-se, sobretudo, em procedimentos especulativos (PELEGRINI, 2008).

A realização de investigações críticas acerca do método procedidas por Popper, Kuhn, Lakatos e Feyerabend, que revelou a ausência de critérios legítimos de cientificidade, dissuadiu-nos da intenção de indagar a respeito de um método científico adequado à Geografia. A existência de um método capaz de conduzir a descobertas científicas revelou-se uma ilusão. Portanto, não é o caso de se proceder de acordo com a sugestão de Massimo Quaini (1983, p. 15), à realização de uma "[...] história dos métodos científicos no campo da geografia".

Se para Kuhn (2000 e 2006) e Feyerabend (1989) tornou-se impraticável a elucidação dos procedimentos metodológicos eminentemente científicos adotados nas disciplinas acadêmicas, ainda mais difícil se tornou a delimitação das supostas ciências a partir da eleição do objeto. Aliás, os filósofos da ciência pós-empiristas sequer cogitaram em fazê-la.

Aparentemente, a perspectiva em que os pós-empiristas do século XX compreenderam as questões de método e objeto também escapou a Milton Santos. Isto pode ser conferido em Por uma geografia nova, quando seu autor se esforça por definir o espaço como objeto de estudo da Geografia. Sua concepção de objeto de estudo para a Geografia envolve a noção de um espaço social, ou espaço humano, como instância social alocada juntamente às demais instâncias: a econômica, a política, a social, a jurídica, etc. Mesmo sem perder de vista a necessidade de apreensão da totalidade, e de se recusar a admitir uma determinação econômica sobre o espaço, sua abordagem reconhece, tacitamente, a impossibilidade de delimitação de um campo científico para sua disciplina a partir da definição de seus métodos.

Se Yves Lacoste preocupou-se com a carência de métodos adequados à Geografia, desta questão se esquivou Milton Santos. No equívoco cometido por Lacoste, Milton Santos não incorreu. Ao invés de indagar sobre o método, Santos (2002) se propõe a discutir o objeto de estudo da Geografia, desenvolvendo uma argumentação que admite a existência de leis próprias para cada instância social e a relativa autonomia das disciplinas: "e como as outras disciplinas, o espaço embora submetido à lei da totalidade, dispõe de uma certa autonomia que se manifesta por meio de leis próprias, específicas de sua própria evolução" (SANTOS, 2002, p. 181). Cada disciplina, em sua visão, corresponde a uma parcela da realidade e cada qual ao seu objeto: "Essa parcela ou aspecto da vida social assim considerado vem a ser o objeto de cada disciplina particular" (SANTOS, 2002, p. 147). Daí seu esforço para definição do espaço como objeto de estudo da Geografia.

A eleição do espaço terrestre, ou, do espaço geográfico, como objeto de estudo da Geografia, dá origem a inúmeras dificuldades, tanto do ponto de vista teórico como do prático. A delimitação de um objeto de estudo de natureza excessivamente ampla não apresenta nenhuma utilidade, uma vez que não impõe restrições. Tratando-se do espaço, não se pode falar exatamente em delimitação, pois as noções de espaço geográfico e espaço terrestre, de modo algum, concentram a pesquisa em determinados limites. Pelo contrário, a amplia.

Se os fenômenos que observamos se apresentam imbricados, se a realidade que percebemos não possibilita a distinção imediata de suas causas, a não ser por um esforço analítico reducionista, 
ousamos isolar os objetos de estudo. Considerando que investigar as relações sociais significa, ao mesmo tempo, estudar suas relações econômicas, políticas, conformadas a partir da história, em determinado ambiente, a partir de quais critérios uma comunidade de pesquisadores pode escolher apenas uma destas instâncias e a eleger como objeto de sua disciplina?

$\mathrm{O}$ desenvolvimento da prática acadêmica no âmbito das ciências sociais tem mostrado que a definição do objeto de estudo para as disciplinas acadêmicas não pode ser respeitada quando do exercício da pesquisa, conforme argumentou Immanuel Wallerstein (1999). Fenômenos anteriormente desconsiderados foram incorporados aos estudos conduzidos em diversas disciplinas, principalmente nas últimas décadas, em face da demanda por explicações mais detalhadas. A interface entre natureza e cultura, que, desde longa data, desperta o interesse dos antropólogos, assim como a consideração dos fatores ambientais, por sociólogos e economistas, tem requerido, por parte de muitos pesquisadores, a realização de aproximações disciplinares.

A preocupação com a influência dos aspectos naturais que, até poucas décadas, era uma prerrogativa apenas dos geógrafos (entre as cientistas sociais), vem sendo gradativamente incorporada pelas demais disciplinas, a exemplo da Economia e da Sociologia. Para diversos economistas, atualmente, a atividade da qual participam só pode ser praticada a partir de uma perspectiva multidimensional e transdisciplinar. Certamente, podemos afirmar que a importância, nos últimos anos, dos estudos de sociologia ambiental no contexto das ciências sociais, representa uma alteração semelhante à que vem ocorrendo no campo da Economia. A valorização da questão ambiental no âmbito de uma disciplina que, historicamente, prescindiu da consideração da natureza, é um evento digno de nota.

À vista disto, a nomeação de um objeto de estudo específico para o domínio da Geografia, revela-se uma tarefa inglória. De modo que, se não conseguimos distinguir e caracterizar o saber geográfico pela verificação dos métodos empregados, por sua vez, também não logramos êxito na sua distinção a partir da delimitação de seu objeto.

\section{CONSIDERAÇÕES FINAIS}

Para nós parece evidente que as posições sustentadas por muitos geógrafos são ainda pautadas pela concepção tradicional de ciência, em flagrante descaso para com as discussões promovidas no campo da filosofia e da arqueologia das ciências humanas, durante o último século. A afirmação de que os fundamentos teóricos da Geografia assentam-se ainda sobre a teoria tradicional permanece válida, mesmo se considerarmos que, na segunda metade do século XX, diversos geógrafos críticos tenham empreendido esforços no sentido de elaborar uma abordagem mais alinhada a alguns princípios do marxismo, procurando aproximar as temáticas geográficas aos problemas práticos do mundo real - especialmente os vividos pelas classes sociais excluídas dos círculos do poder econômico e político.

Ainda que esse movimento de renovação tenha sido responsável por um reconhecido esforço de equacionamento no campo teórico, não encontramos os fundamentos desta disciplina senão na matriz comum às demais disciplinas, que por sua vez, assenta-se, de um lado, sobre a falsa ideia da existência do método científico, e, de outro, na busca de definição de um objeto de estudo único.

É fato que a história do pensamento geográfico tem uma longa história. Porém, suas raízes estão cravadas nos referenciais da teoria tradicional. Se, no âmbito da Geografia, a imprecisão dos principais conceitos e noções utilizados dificultou a estruturação coerente dos programas de pesquisa, como podemos conceber a existência de uma teoria da Geografia? Em vista disso, entendemos que a história do pensamento geográfico, ao contrário do que muitos acreditam, não corresponde à teoria da Geografia. O que pode ser dito da história do pensamento geográfico é que ela diz respeito, especialmente, à história dos discursos geográficos. 


\section{REFERÊNCIAS BIBLIOGRÁFICAS}

CAPEL, Horácio. Filosofía y ciencia en la Geografía contemporánea. 2. ed. Barcelona: Barcanova, 1983. CHALMERS, Alan F. O que é ciência, afinal? Tradução de Raul Fiker. São Paulo: Brasiliense, 1993.

DEMANGEON, Albert. Uma definição de Geografia humana. Tradução de. In: CHRISTOFOLETTI, Antonio (org.). Perspectivas da Geografia. São Paulo: DIFEL, 1982.

DOMINGUES, Ivan. O grau zero do conhecimento: o problema da fundamentação das ciências humanas. São Paulo: Loyola, 1991.

FEYERABEND, Paul K. Contra o método. Tradução de Octanny S. da Mota e Leônidas Hegenberg. 3. ed., Rio de Janeiro: Francisco Alves, 1989.

FEYERABEND, Paul K. Matando o tempo: uma autobiografia. Tradução de Raul Fiker. São Paulo: Fundação Editora da Universidade Estadual Paulista, 1996.

FOUCAULT, Michel. As palavras e as coisas: uma arqueologia das ciências humanas. Tradução de Salma Tannus Muchail. 8. ed. São Paulo: Martins Fontes, 1999.

FOUCAULT, Michel. A arqueologia do saber. 7. ed. Tradução de Luiz Felipe Baeta Neves. Rio de Janeiro: Forense Universitária, 2005.

GEORGE, Pierre. Os métodos da Geografia. Tradução de Heloysa de Lima Dantas. São Paulo: Difusão Européia do Livro, 1978.

GOMES, Paulo César da Costa. Geografia e modernidade. Rio de Janeiro: Bertrand Brasil, 1996.

HABERMAS, Jürgen. Conhecimento e interesse. Tradução de José N. Heck. Rio de Janeiro: Zahar Editores, 1982.

HABERMAS, Jürgen. O discurso filosófico da modernidade: doze lições. Tradução de Luiz Sérgio Repa e Rodnei Nascimento. São Paulo: 2000.

HARVEY, David. Condição pós-moderna: uma pesquisa sobre a origem da mudança cultural. Tradução Adail Ubirajara Sobral e Maria Stela Gonçalves. 6. ed. São Paulo: Loyola, 1996.

HISSA, Cássio Eduardo Viana. A mobilidade das fronteiras: inserções da geografia na crise da modernidade. Belo Horizonte: Editora da UFMG, 2002.

HUME, David. Investigação acerca do entendimento humano. Tradução de Anoar Aiex. São Paulo: Editora Nacional, Ed. da Universidade de São Paulo, 1972.

JOHNSTON, R. J. Geografia e geógrafos: a geografia humana anglo-americana desde 1945. Tradução de Oswaldo Bueno Amorim Filho. São Paulo: DIFEL, 1986.

KANT, Immanuel. Crítica da razão pura. Tradução de Manuela Pinto dos Santos e Alexandre Fradique Morujão. 3. ed. Lisboa: Fundação Calouste Gulkenkian, 1994.

KUHN, Thomas S. A Estrutura das Revoluções Científicas. Tradução de Beatriz Vianna Boeira e Nelson Boeira. 5. ed. São Paulo: Editora Perspectiva, 2000.

KUHN, Thomas S. O caminho desde a Estrutura: ensaios filosóficos, 1970-1993, com uma entrevista autobiográfica. Tradução de César Mortari. São Paulo: Editora UNESP, 2006.

LACOSTE, Yves. A Geografia. In : CHÂTELET, François. A filosofia das ciências sociais. Tradução de Hilton Ferreira Japiassú. Rio de Janeiro : Zahar Editores, 1981.

LACOSTE, Yves. Les géographes, la science et l'illusion. Hérodote, n. 76, jan-mar 1995. p. 3-21.

LAKATOS, Imre. O falseamento e a metodologia dos programas de pesquisa científica. In: LAKATOS, Imre \& MUSGRAVE, Alan. A crítica e o desenvolvimento do conhecimento. Tradução de Octávio Mendes Cajado. São Paulo: Cultrix: Editora da Universidade de São Paulo, 1979. pp. 109-243.

LAUDAN, Larry. Teorias do método científico de Platão a Mach. In: Cadernos de História e Filosofia da Ciência, Série 3, v. 10, n. 2, jul - dez, 2000. p. 9-140.

MASTERMAN, Margaret. A natureza do paradigma. In: LAKATOS, Imre \& MUSGRAVE, Alan. A crítica e o desenvolvimento do conhecimento. Tradução de Octávio Mendes Cajado. São Paulo: Cultrix: Editora da Universidade de São Paulo, 1979. pp. 72-108. 
MORAES, Antônio Carlos Robert. A gênese da geografia moderna. São Paulo: Bertrand Brasil, 1996.

PELEGRINI, Djalma Ferreira. Geografia e Saberes Modernos: a inserção da complexidade nos discursos geográficos. Tese (doutorado em Geografia). Universidade Federal de Uberlândia (UFU). Uberlândia, 2008.

POPPER, Karl Raymund. A lógica da pesquisa científica. Tradução de Leônidas Hegenberg e Octanny Silveira da Mota. 2. ed., São Paulo: Cultrix, 1972.

POPPER, Karl. Lógica das ciências sociais. Tradução de Estevão de Rezende Martins, Apio Cláudio Muniz Acquarone Filho, Vilma de Oliveira Moraes e Silva. Rio de Janeiro: Tempo Brasileiro; Brasília: Ed. Universidade de Brasília, 1978.

QUAINI, Massimo. A Construção da Geografia Humana. Tradução de Liliana Laganá Fernandes. Rio de Janeiro: Paz e Terra, 1983.

SANTOS, Milton. Por uma Geografia Nova: da crítica da Geografia a uma Geografia crítica. São Paulo: EDUSP, 2002.

VIDAL DE LA BLACHE, Paul. Princípios de Geografia Humana. Tradução de Fernandes Martins. 2. ed. Lisboa (Portugal): Edições Cosmos, 1954.

WALLERSTEIN, Immanuel. Análise dos sistemas mundiais. In: GIDDENS, Anthony e TURNER, Jonathan (Org). Teoria social hoje; Tradução de Gilson César C. de Sousa. São Paulo: Editora UNESP, 1999. p. 447-470.

WOOLDRIDGE, S.W.; GORDON EAST, W. Espírito e propósitos da Geografia. Tradução de Thomaz Newlands Neto. 2. ed. Rio de Janeiro: Zahar Editores, 1967. 